\title{
Simultaneous Determination of Uric Acid and Xanthine Using a Poly(Methylene Blue) and Electrochemically Reduced Graphene Oxide Composite Film Modified Electrode
}

\author{
Gen Liu, Wei Ma, Yan Luo, Deng-ming Sun, and Shuang Shao \\ Department of Chemistry and Materials Science, Huaibei Normal University, Huaibei 235000, China \\ Correspondence should be addressed to Gen Liu; liugen7084@126.com and Deng-ming Sun; sundengming@126.com
}

Received 29 July 2014; Revised 9 October 2014; Accepted 19 October 2014; Published 11 November 2014

Academic Editor: Chih-Ching Huang

Copyright @ 2014 Gen Liu et al. This is an open access article distributed under the Creative Commons Attribution License, which permits unrestricted use, distribution, and reproduction in any medium, provided the original work is properly cited.

\begin{abstract}
Poly(methylene blue) and electrochemically reduced graphene oxide composite film modified electrode (PMB-ERGO/GCE) was successfully fabricated by electropolymerization and was used for simultaneous determination of uric acid (UA) and xanthine (Xa). Based on the excellent electrocatalytic activity of PMB-ERGO/GCE, the electrochemical behaviors of UA and Xa were studied by cyclic voltammetry (CV) and square wave voltammetry (SWV). Two anodic sensitive peaks at $0.630 \mathrm{~V}$ (versus $\mathrm{Ag} / \mathrm{AgCl}$ ) for $\mathrm{UA}$ and $1.006 \mathrm{~V}$ (versus $\mathrm{Ag} / \mathrm{AgCl}$ ) for Xa were given by $\mathrm{CV}$ in $\mathrm{pH} 3.0$ phosphate buffer. The calibration curves for UA and Xa were obtained in the range of $8.00 \times 10^{-8} \sim 4.00 \times 10^{-4} \mathrm{M}$ and $1.00 \times 10^{-7} \sim 4.00 \times 10^{-4} \mathrm{M}$, respectively, by SWV. The detection limits for UA and Xa were $3.00 \times 10^{-8} \mathrm{M}$ and $5.00 \times 10^{-8} \mathrm{M}$, respectively. Finally, the proposed method was applied to simultaneously determine UA and $\mathrm{Xa}$ in human urine with good selectivity and high sensitivity.
\end{abstract}

\section{Introduction}

Graphene oxide (GO) and graphene are promising materials with many interesting properties for applications [1]; for example, they have nice compatibility with biological materials such as amino acids [2] and proteins [3]. Although its badly electrical conductivity limits the usage of graphene oxide, many efforts have improved the methods to obtain the reduced graphene oxide, such as chemical reduced $[4,5]$, UV-induced photocatalytic reduced [6], and electrochemical reduced [7]. Electrochemically reduced graphene oxide could be prepared based on the research of Zhou et al. [8]. Moreover, Casero et al. immersed a graphite working electrode in GO dispersion and controlled an appropriate cathodic potential in 12 hours to obtain reduced graphene oxide [9].

The electron pair or electron cloud overlapping between dye molecules and graphite electrode strengthened their adsorption affinity and accelerated electron transfer rate [10]. Because of the $\pi-\pi$ noncovalent interaction, some electroactive water-soluble aromatic dyes could absorb on the surface of carbon material, such as the combination of Toluidine blue $\mathrm{O}$ and multiwall carbon nanotube [11]. Methylene blue
(MB), one of the phenoxazine biological dyes, is an electron carrier activation. Sun et al. had applied poly(methylene blue) functionalized graphene modified carbon ionic liquid electrode to determine dopamine. The modified electrode exhibited better electrochemical performances with higher conductivity and lower electron transfer resistance [12]. It indicates that poly(methylene blue) functionalized graphene possesses distinct properties in electrochemical field.

Uric acid (UA, $\mathrm{C}_{5} \mathrm{H}_{4} \mathrm{~N}_{4} \mathrm{O}_{3}$ ) is one of the final metabolites of proteins and nucleic acids. It is mainly excreted by kidney and to a less extent by liver. To most mammals and birds, UA is biologically decomposed to allantoin by the action of uricase and then decomposed to $\mathrm{NH}_{3}, \mathrm{CO}_{2}$, and $\mathrm{H}_{2} \mathrm{O}$. However, the further step is not applicable in humans and apes because of uricase insufficiency. Consequently, UA is the final metabolic product of purine. The amount of UA in human body has great clinical values since it has a bearing in the diagnosis of gout, Lesch-Nyhan syndrome, urolithiasis, kidney damage, leukemia, lymphoma [13-15], and so forth.

Xanthine $\left(\mathrm{Xa}, \mathrm{C}_{5} \mathrm{H}_{4} \mathrm{~N}_{4} \mathrm{O}_{2}\right.$ ) mainly exists in the animals' blood, liver, and urine and is an important metabolic intermediate of the purine nucleotide and deoxynucleotide. 
In addition, the decomposition of adenosine triphosphate (ATP) can also produce Xa [16]. In clinical diagnosis, Xa usually acts as a sensitive indicator for some clinical disorders such as perinatal asphyxia and adult respiratory distress syndrome [17-19]. As the metabolic precursor of UA, Xa determines the level of UA in body fluid. Thus, developing a stable, sensitive, and selective sensor for UA and Xa has considerable importance for clinical analysis. Previously, various methods for the determination of UA and Xa have been reported, such as fluorimetry [20, 21], spectrophotometry $[22,23]$, enzyme assay $[15,24]$, chromatography $[25,26]$, and electrochemical methods [27-29]. However, some inherent problems limit their applications, which includes expensive instruments, complex operations, and personnel training.

In this work, we fabricated poly(methylene blue) and electrochemically reduced graphene oxide composite film modified electrode, which comprised not only excellent electrocatalytic activity for the oxidation of UA and Xa, but also good sensitivity, wide linearity, high selectivity, and remarkable reproducibility. Thus, this modified electrode was satisfactorily used for the simultaneous determination of UA and $\mathrm{Xa}$ in human urine by square wave voltammetry (SWV).

\section{Experimental}

2.1. Instruments and Chemicals. Electrochemical measurements were performed with a BAS $100 \mathrm{~B} / \mathrm{W}$ electrochemical workstation (BAS, USA). A conventional three-electrode system was used for all electrochemical experiments, which consisted of an $\mathrm{Ag} / \mathrm{AgCl}$ (saturated $\mathrm{KCl}$ ) as the reference electrode, a platinum wire as the auxiliary electrode, and a bare GCE ( $3 \mathrm{~mm}$ in radius) or modified GCE as working electrode. The morphology of the samples was observed using scanning electron microscopes (SEM) from JSM-6610LV (JEOL, Japan). The UV-visible spectra were obtained by UV3600 UV-VIS-NIR spectrophotometer (Shimadzu, Japan). All pH measurements were performed using a PHS-3C digital pH meter (Shanghai Leici Device Works, China).

Graphene oxide dispersion $\left(2 \mathrm{mg} \cdot \mathrm{mL}^{-1}\right.$; dispersing agent: water; radius: $1 \sim 5 \mu \mathrm{m}$; thickness: $0.8 \sim 1.2 \mathrm{~nm}$; single layer ratio: 99\%; purity: 99\%) was obtained from Nanjing XFNANO Materials Technology Company, China. MB, $\mathrm{UA}$, and Xa were purchased from Sigma-Aldrich.All other chemicals were used of analytical grade. Double distilled water was used throughout the experiments. The $\mathrm{pH}$ of phosphate buffered solution (PBS) was adjusted with $0.1 \mathrm{M}$ $\mathrm{H}_{3} \mathrm{PO}_{4}$ and $0.1 \mathrm{M} \mathrm{NaOH}$. All experiments were carried out at room temperature.

2.2. Preparation of $P M B-E R G O / G C E$. The bare GCE was polished with $0.05 \mu \mathrm{m} \alpha$-alumina powder, until a mirror-like finish, rinsed with $1: 1 \mathrm{HNO}_{3}$ solution, ethanol, and doubly distilled water in an ultrasonic aqueous bath successively, and again rinsed with water before it was used. $1.00 \mathrm{mg} \cdot \mathrm{mL}^{-1}$ GO in $0.1 \mathrm{M}$ PBS ( $\mathrm{pH}$ 6.0) was ultrasonicated for $5 \mathrm{~min}$; then an appropriate amount of $\mathrm{MB}$ was added to form an aqueous solution $\left(2.00 \times 10^{-3} \mathrm{M}\right)$, followed by ultrasonication for another $5 \mathrm{~min}$. Finally, the polymeric film was electropolymerized by sweeping from 0.7 to $-1.2 \mathrm{~V}$ at a scan rate of $0.10 \mathrm{~V} \cdot \mathrm{s}^{-1}$ for 11 cycles using cyclic voltammetry. After polymerization, the modified electrode was removed, rinsed thoroughly with double distilled water, and air-dried. Finally the poly(methylene blue) and electrochemically reduced graphene oxide composite film modified electrode (PMBERGO/GCE) was successfully prepared.

\section{Results and Discussion}

3.1. Characterizations of $P M B-E R G O / G C E$. Compared with lower and higher electropolymerized cathodic potential, potential of $-1.2 \mathrm{~V}$ was enough to guarantee good catalytic ability of PMB-ERGO/GCE toward UA and Xa. Besides, lower cathodic potential usually produced hydrogen bubbles on the surface of electrodes without further improving the responses to UA and $\mathrm{Xa}$. In fact, these bubbles not only influenced the electric current density, but also damaged the modified film.

Figure 1(a) gives the cyclic voltammograms of electrochemical polymerization for poly(methylene blue) film modified electrode (PMB/GCE), and Figure 1(b) is PMBERGO/GCE. It can be seen in Figure 1(a) that a pair of sharp redox peaks of MB appear at $0.162 \mathrm{~V}$ (anodic peak) and $-0.181 \mathrm{~V}$ (cathodic peak) in the first cycle. This redox reaction possesses poor reversibility in that a large and obvious difference exists in the redox peak currents. In Figure 1(b), however, the anodic peak (at $0.151 \mathrm{~V}$ ) and the cathodic peak (at $0.022 \mathrm{~V}$ ) of $\mathrm{MB}$ are both wide; moreover, GO has an irreversible cathodic peak at $-1.079 \mathrm{~V}$. In the following cycles, the cathodic peak current of GO decreases, the redox peak currents of $\mathrm{MB}$ increase, and finally these curves are not changed because of the increasing thickness of modified film and the deceleration of the rate of deposition.

It is well-known that some oxygen-containing functional groups, such as $-\mathrm{OH},-\mathrm{COOH},-\mathrm{C}=\mathrm{O},-\mathrm{C}-\mathrm{O}-\mathrm{C}-$, which exist in graphene oxide, can lead to the large amount of $s p^{3}$-hybridized carbon atoms. Electrochemical reduction is a technique to remove these oxygen functional groups and can restore $s p^{2}$-hybridized carbon atoms, which can change graphene oxide to graphene. After polymerization, the electrochemically reduced graphene oxide (ERGO) is prepared on the surface of electrodes.

Figure 2 exhibits UV-visible spectra curves of $1.50 \times$ $10^{-5} \mathrm{M} \mathrm{MB}$ and $0.02 \mathrm{mg} \cdot \mathrm{mL}^{-1} \mathrm{GO}$ and the mixture solution of $1.50 \times 10^{-5} \mathrm{M} \mathrm{MB}$ and $0.02 \mathrm{mg} \cdot \mathrm{mL}^{-1} \mathrm{GO}$. MB gives two absorption peaks at $662 \mathrm{~nm}(1)$ and $616 \mathrm{~nm}$ (2), and peak 1 is much spikier and stronger than peak 2 . The absorption peaks might originate from the corresponding monomer and dimer of $\mathrm{MB}$, respectively [35]. GO has no obvious absorption. After $\mathrm{GO}$ is added to $\mathrm{MB}$ solution, the absorption peaks of $\mathrm{MB}$ decline drastically, but still at the same wavelength, implying that some interactions occur between $\mathrm{MB}$ and $\mathrm{GO}$.

SEM images of GCE, PMB/GCE, and PMB-ERGO/GCE are displayed in Figure 3. PMB film is smooth, dense, and uniform and PMB-ERGO film shows a rough surface feature with bulges, which indicates that ERGO is embedded into the polymer structure of $\mathrm{MB}$ and increases the specific surface 


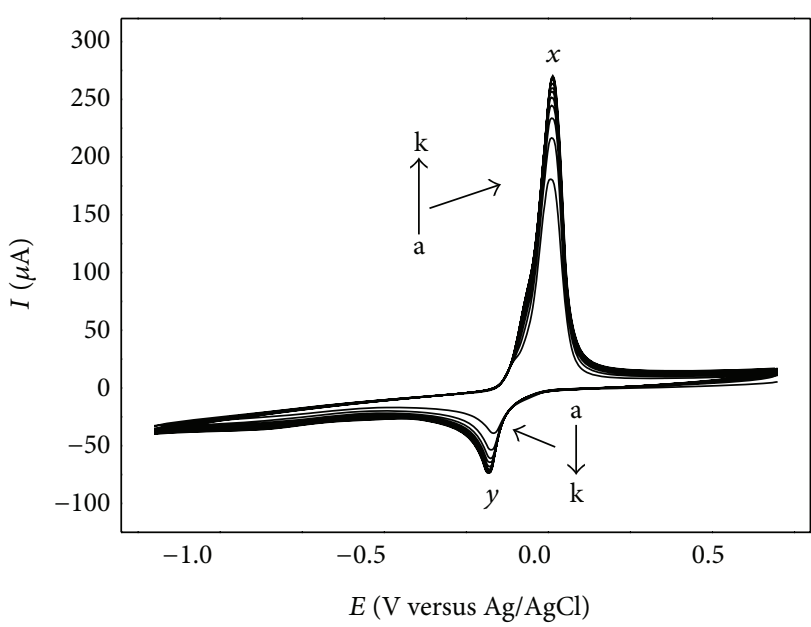

(a)

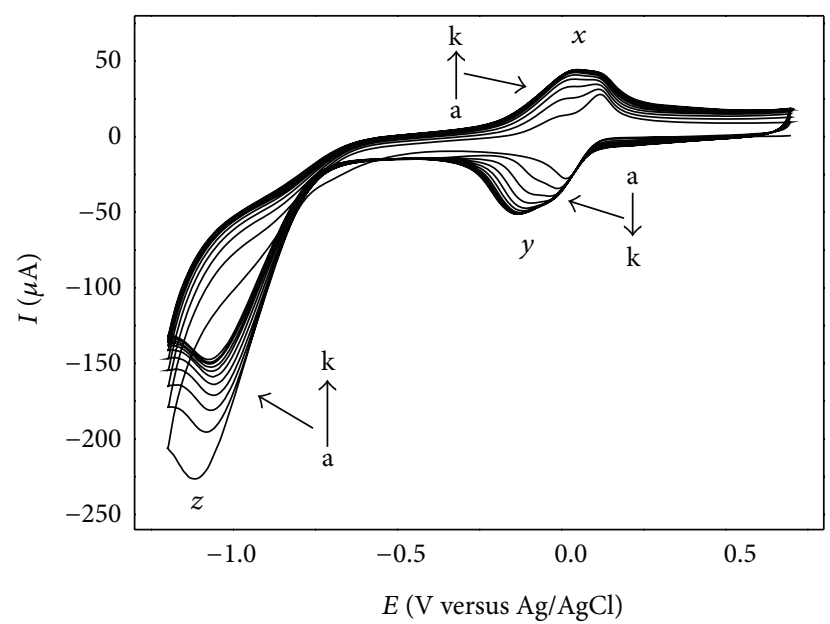

(b)

Figure 1: CVs of PMB/GCE (a) and PMB-ERGO/GCE (b) in the polymerization process at a scan rate of $0.10 \mathrm{~V} \cdot \mathrm{s}^{-1}$ for $11 \mathrm{cycles}($ from a to $\mathrm{k}) ; x$ : anodic peak of MB; $y$ : cathodic peak of MB; $z$ : cathodic peak of GO.

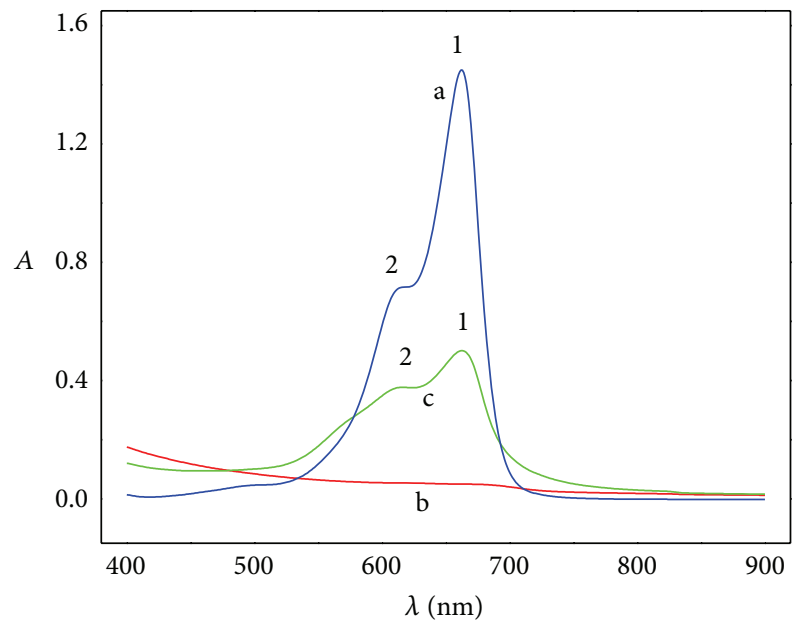

Figure 2: Comparison of UV-visible spectra of MB (a), GO (b), and the mixture solution of MB and GO (c) in $1.0 \mathrm{~cm}$ light path length cell.

area. Compared with bare GCE, the electropolymerized films of PMB and PMB-ERGO were colorful and could be observed by naked eye, suggesting the films had been successfully adhered to the electrode surface.

Figure 4 depicts the electrochemical impedance spectra of GCE, PMB/GCE, ERGO/GCE, and PMB-ERGO/GCE, and their corresponding impedance values were $1212 \Omega, 233.1 \Omega$, $96.4 \Omega$, and $162.5 \Omega$, respectively. These data imply that the modified films of PMB, ERGO, and PMB-ERGO had accelerated the rate and lowered the activation energy of electron transfer, particularly ERGO.

3.2. Electrocatalytic Activity of UA and Xa at Different Electrodes. Figure 5 shows the CV responses of the bare GCE, $\mathrm{PMB} / \mathrm{GCE}$, ERGO/GCE, and PMB-ERGO/GCE toward
TABLE 1: Detail data of cyclic voltammograms at different electrodes.

\begin{tabular}{lcccc}
\hline \multirow{2}{*}{ Electrode } & \multicolumn{2}{c}{$\mathrm{UA}$} & \multicolumn{2}{c}{$\mathrm{Xa}$} \\
& $E: \mathrm{V}$ & $I: \mu \mathrm{A}$ & $E: \mathrm{V}$ & $I: \mu \mathrm{A}$ \\
\hline Bare GCE & 0.638 & 4.542 & 1.004 & 3.569 \\
PMB/GCE & 0.622 & 24.53 & 0.998 & 28.79 \\
ERGO/GCE & 0.632 & 30.56 & 1.004 & 34.46 \\
PMB-ERGO/GCE & 0.630 & 33.91 & 1.006 & 36.81 \\
\hline
\end{tabular}

$2.00 \times 10^{-4} \mathrm{M}$ UA and $2.00 \times 10^{-4} \mathrm{M}$ Xa. Table 1 lists the anodic peak currents and potentials of different electrodes. It is noticed that the anodic peak potentials on the four electrodes are close. However, the anodic peak currents of $\mathrm{UA}$ and $\mathrm{Xa}$ on PMB-ERGO/GCE are much higher than others, indicating PMB-ERGO/GCE has the greatest electrochemical activity, which ought to be attributed to the synergistic effects of PMB and ERGO. On PMB-ERGO/GCE, $\mathrm{Epa}(\mathrm{UA})=0.630 \mathrm{~V}$, and $\mathrm{Epa}(\mathrm{Xa})=1.006 \mathrm{~V}$, their peaks were separated by $0.376 \mathrm{~V}$. This result indicates that the simultaneous determination for UA and Xa could be achieved without separation. Combining the nice conductivity, PMBERGO/GCE is appropriate to be employed to investigate the electrochemical behavior of UA and Xa.

3.3. Effective Area of Electrodes. GCE, PMB/GCE, ERGO/ GCE, and PMB-ERGO/GCE were immerged into the solution containing $5.0 \times 10^{-3} \mathrm{M} \mathrm{K}_{3}\left[\mathrm{Fe}(\mathrm{CN})_{6}\right]$ and $1.0 \mathrm{M} \mathrm{KCl}$, followed by sweeping with cyclic voltammetry. The effective area of electrode can be calculated from the RandlesSevcik plot: $I p=2.69 \times 10^{5} n^{3 / 2} A D^{1 / 2} v^{1 / 2} C$, wherein $i_{p}$ is current in amps (A), $n$ is number of electrons transferred of $\mathrm{K}_{3}\left[\mathrm{Fe}(\mathrm{CN})_{6}\right]$ in the redox event (usually is 1 ), $A$ is electrode effective area, $D$ is diffusion coefficient $\left(7.6 \times 10^{-6} \mathrm{~cm}^{2} \cdot \mathrm{s}^{-1}\right)$, $C$ is concentration $(5 \mathrm{mM})$, and $v$ is scan rate $\left(0.05 \mathrm{~V} \cdot \mathrm{s}^{-1}\right)$. The effective areas for GCE, PMB/GCE, ERGO/GCE, and 

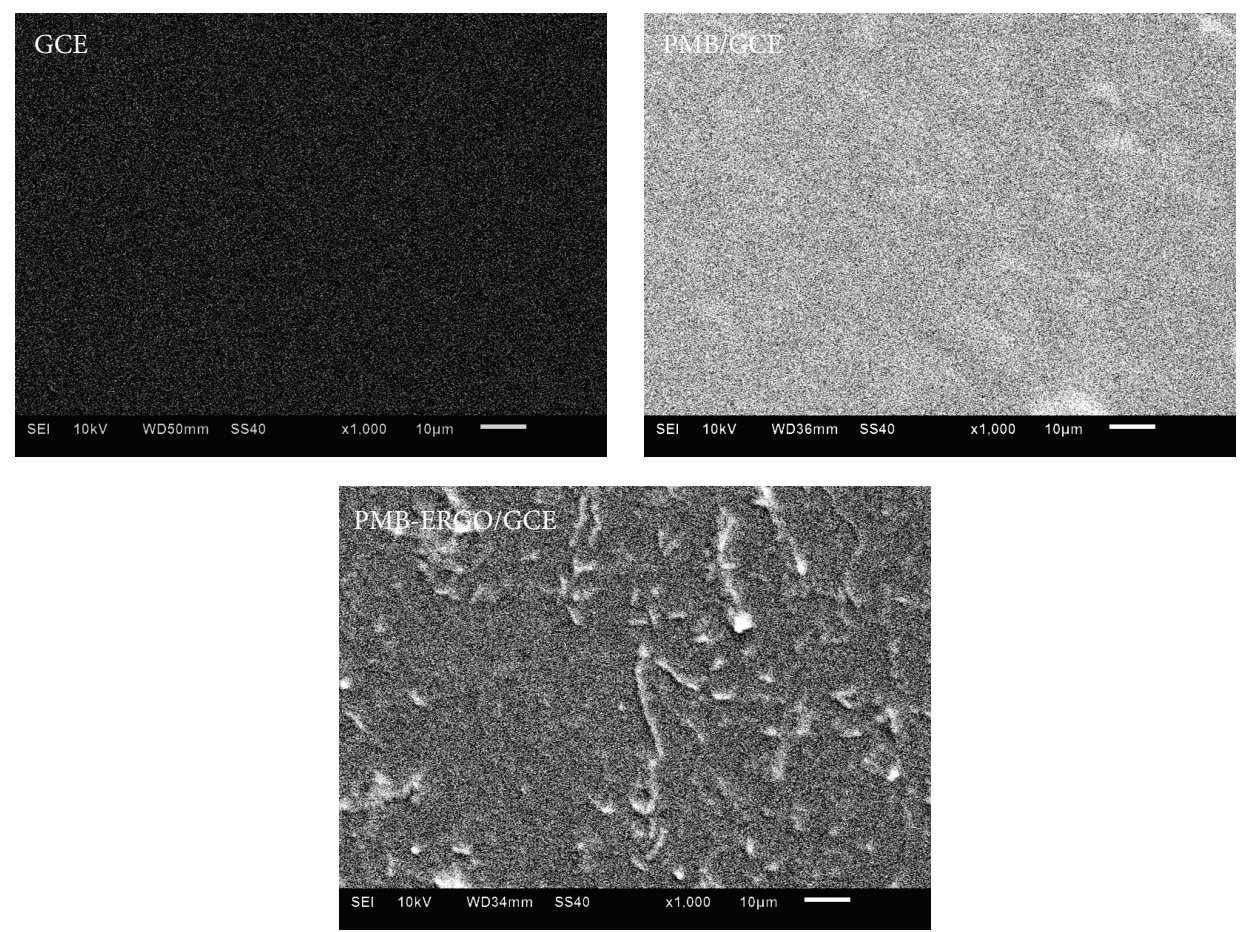

Figure 3: SEM images of GCE, PMB/GCE, and PMB-ERGO/GCE.

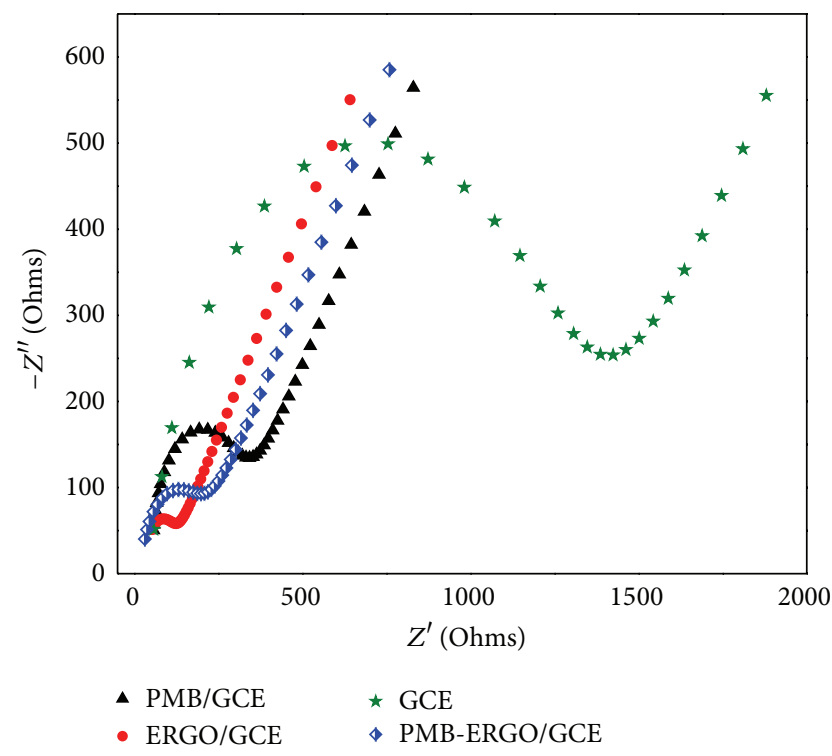

Figure 4: EIS of GCE, PMB/GCE, ERGO/GCE, and PMB-ERGO/ GCE in $5.0 \times 10^{-3} \mathrm{M} \mathrm{K}_{3}\left[\mathrm{Fe}(\mathrm{CN})_{6}\right], 1.0 \mathrm{M} \mathrm{KCl}$ solution with initial $E$ for $150 \mathrm{mV}$, high frequency for $2000 \mathrm{~Hz}$, low frequency for $0.05 \mathrm{~Hz}$, and A.C. amplitude for $150 \mathrm{mV}$.

PMB-ERGO/GCE were $0.0941 \mathrm{~cm}^{2}, 0.1906 \mathrm{~cm}^{2}, 0.2088 \mathrm{~cm}^{2}$, and $0.2291 \mathrm{~cm}^{2}$, respectively. PMB-ERGO/GCE contains the largest effective area, which presumably accounts for its excellent electrocatalytic activity.

3.4. Effect of $p H$. In most cases, the electrolyte $\mathrm{pH}$ is an important condition to the electrochemical reaction. The

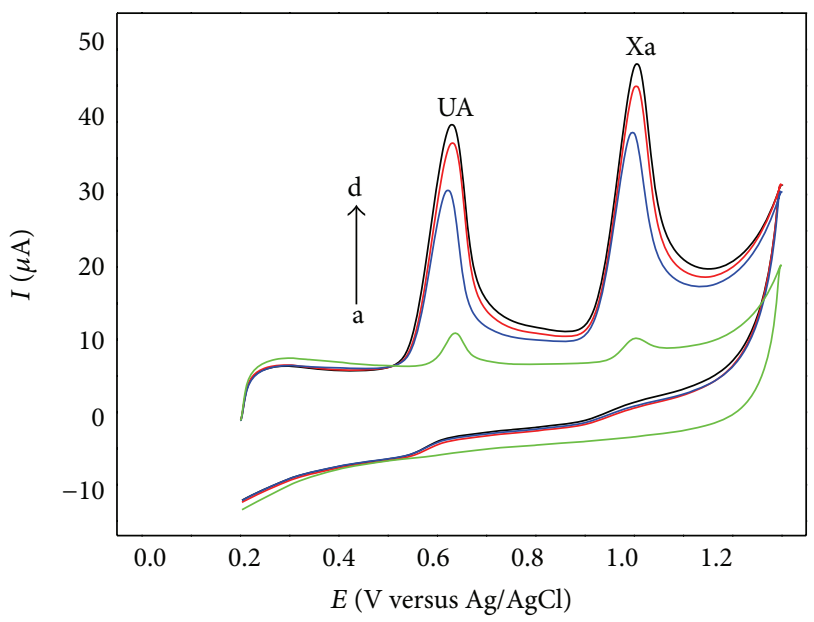

(d) PMB-ERGO/GCE

(b) $\mathrm{PMB} / \mathrm{GCE}$

(c) $\mathrm{ERGO} / \mathrm{GCE}$

(a) GCE

Figure 5: CVs of bare GCE, PMB/GCE, ERGO/GCE, and PMB$\mathrm{ERGO/GCE}$ in the mixture solution of UA and $\mathrm{Xa}$ and PBS ( $\mathrm{pH} 3.0$ ) at a scan rate of $0.14 \mathrm{~V} \cdot \mathrm{s}^{-1}$ with quiet time for $2 \mathrm{~min}$.

cyclic voltammograms of $5.00 \times 10^{-5} \mathrm{M} \mathrm{UA}$ and $1.00 \times$ $10^{-4} \mathrm{M} \mathrm{Xa}$ were recorded from $\mathrm{pH} 2.0$ to 8.0. As shown in Figure 6 , the anodic peak potentials shift in negative direction with a rising value of $\mathrm{pH}$, suggesting that protons have participated in electrode reactions. The anodic peak current of UA increases up to pH 3.0 and then decreases. However, the anodic peak current of Xa decreases in response to increasing $\mathrm{pH}$. Table 2 lists the relationship between peak potential and 


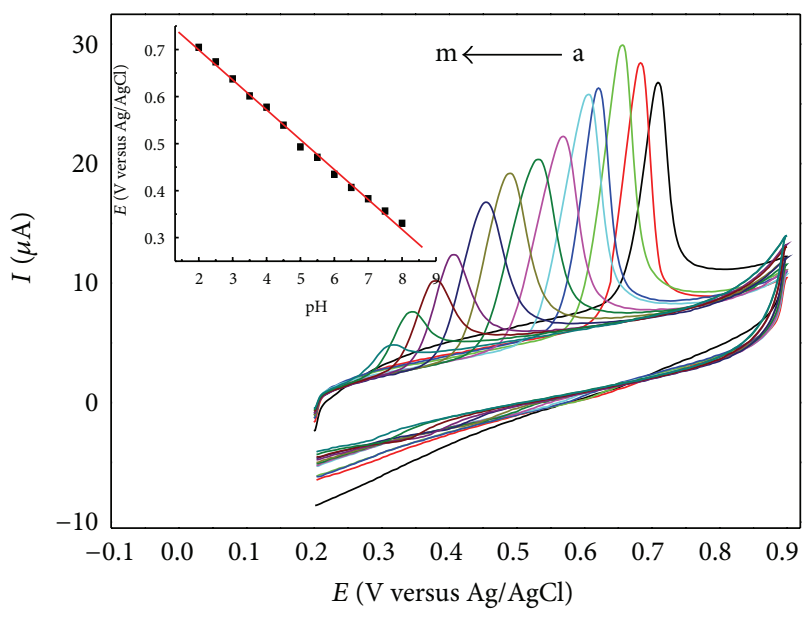

(a)

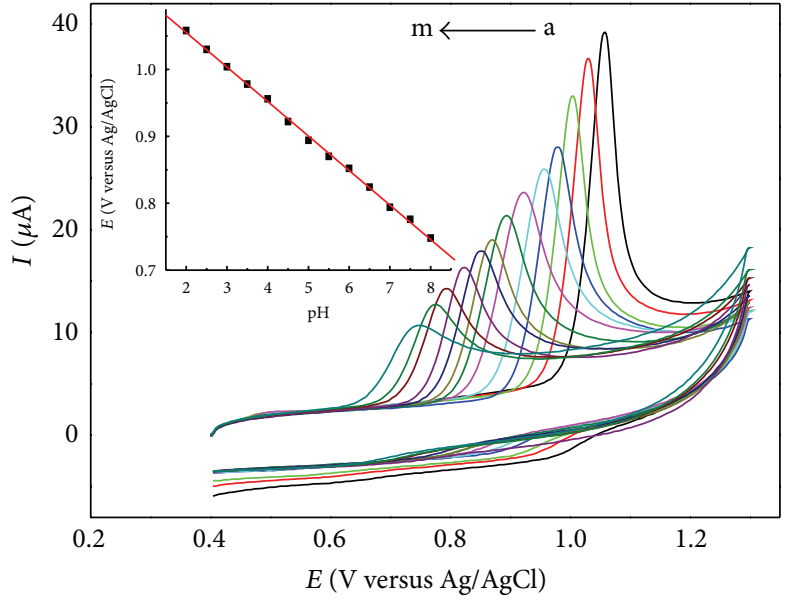

(b)

Figure 6: CVs of UA (a) and Xa (b) with different $\mathrm{pH}$. Insets show the calibration plots of $E$ - $p H$. From a to m: $\mathrm{pH}=2.0,2.5,3.0,3.5,4.0,4.5$, $5.0,5.5,6.0,6.5,7.0,7.5,8.0$.

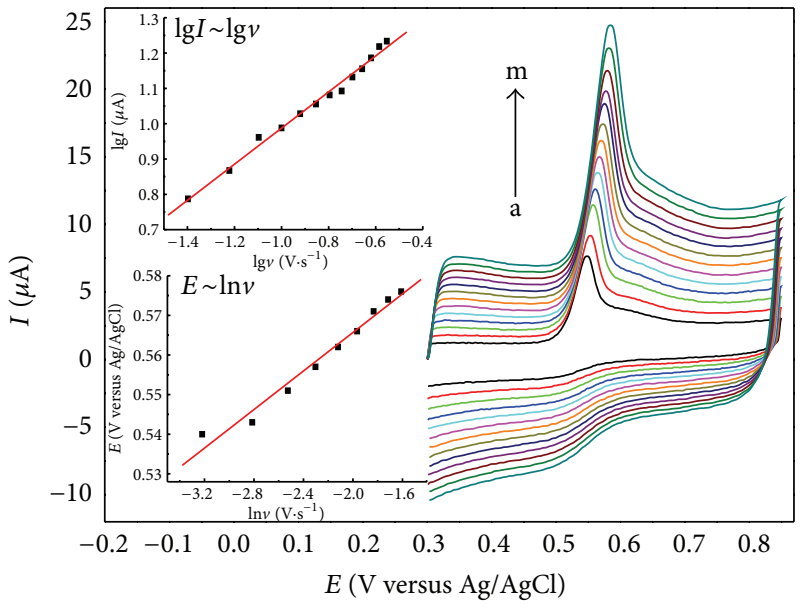

(a)

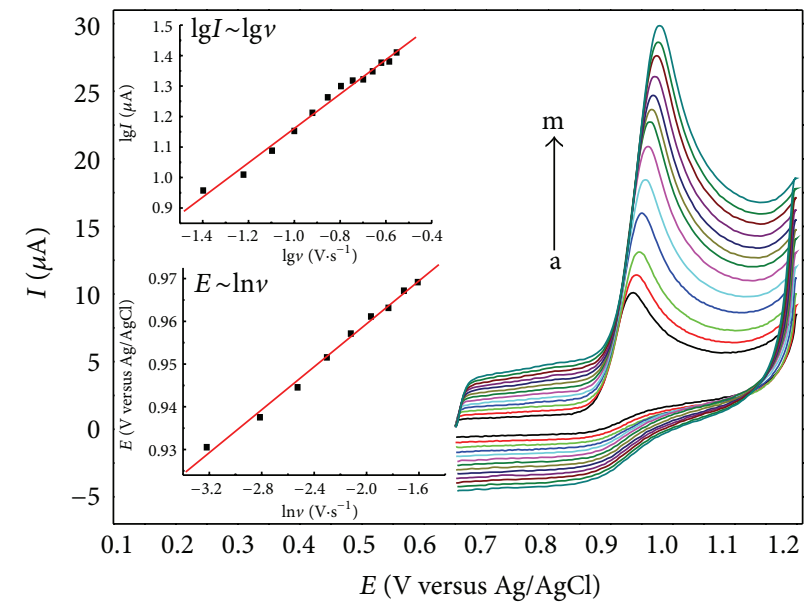

(b)

Figure 7: CVs for UA (a) and Xa (b) at different scan rate in PBS (pH 3.0). Insets show the calibration plots of lgI-lgv and E-lnv. From a to m: $0.04,0.06,0.08,0.10,0.12,0.14,0.16,0.18,0.20,0.22,0.24,0.26,0.28$.

TABLE 2: The relationship between peak potential and $\mathrm{pH}$ of UA and Xa.

\begin{tabular}{|c|c|c|c|c|}
\hline Analye & $\begin{array}{c}\text { Scan rate } \\
v: \mathrm{V} \cdot \mathrm{s}^{-1}\end{array}$ & $\begin{array}{c}\text { The } \\
\text { range of } \\
\text { pH }\end{array}$ & $\begin{array}{c}\text { Linear regression } \\
\text { equation } \\
E: \mathrm{V}\end{array}$ & $\begin{array}{c}\text { Correlation } \\
\text { coefficient }\end{array}$ \\
\hline $\mathrm{UA}$ & \multirow{2}{*}{0.14} & \multirow{2}{*}{$2.0 \sim 8$. } & $=0.8263$ & 0.9942 \\
\hline $\mathrm{Xa}$ & & & $E=1.158-0.05156 \mathrm{pH}$ & 0.9916 \\
\hline
\end{tabular}

pH of UA and Xa. Based on the analysis above, pH 3.0 and pH 2.0 were used in individual determination for UA and $\mathrm{Xa}$, respectively, and $\mathrm{pH} 3.0$ was used in their simultaneous determination.

3.5. Effect of Scan Rates. To investigate the effect of scan rate on the electrochemical behavior of UA and Xa $\left(2.50 \times 10^{-5} \mathrm{M}\right)$ on PMB-ERGO/GCE, cyclic voltammograms were performed by various potential scan rates. Figure 7 shows the anodic peak potential shifts to positive region with increasing scan rates; in addition, the anodic peak current increases at the same time. The relationships between scan rate, peak current, and peak potential are expressed with equations in Table 3.

The slope values approximate to 0.5 in equations of $\lg I$ $\lg v$, which clearly reveals that the electron transfer reactions of UA and $\mathrm{Xa}$ are both controlled by diffusion. Formula $R T /(\alpha n F)$ is usually used to estimate the slope in $E$ - $\ln v$ relationship [36]; herein, $n$ is the reaction electron number, $F$ is Faraday constant, $R$ is gas constant, and $\alpha$ represents electron transfer coefficient (usually is 0.5 ). The real reaction electron numbers of UA and Xa were calculated to be 1.964 and 1.913, respectively. Their theoretical reaction electron numbers should be 2. According to literatures [27, 37, 38], 
TABLE 3: The relationship between scan rate, peak current, and peak potential.

\begin{tabular}{|c|c|c|c|c|c|c|}
\hline \multirow{3}{*}{ Analye } & \multicolumn{3}{|c|}{ The relationship between scan rate and peak current } & \multicolumn{3}{|c|}{ The relationship between scan rate and peak potential } \\
\hline & \multirow{2}{*}{$\begin{array}{c}\text { Scan rate } \\
\text { range } \\
v: \mathrm{V} \cdot \mathrm{s}^{-1}\end{array}$} & $\begin{array}{l}\text { Linear regression } \\
\text { equation }\end{array}$ & \multirow{2}{*}{$\begin{array}{c}\text { Correlation } \\
\text { coefficient }\end{array}$} & \multirow{2}{*}{$\begin{array}{l}\text { Scan rate } \\
\text { range } \\
v: \mathrm{V} \cdot \mathrm{s}^{-1}\end{array}$} & $\begin{array}{c}\text { Linear regression } \\
\text { equation }\end{array}$ & \multirow{2}{*}{$\begin{array}{l}\text { Correlation } \\
\text { coefficient }\end{array}$} \\
\hline & & $I: \mu \mathrm{A} \quad v: \mathrm{V} \cdot \mathrm{s}^{-1}$ & & & $E: \mathrm{V} \quad v: \mathrm{V} \cdot \mathrm{s}^{-1}$ & \\
\hline UA & \multirow{2}{*}{$0.04 \sim 0.28$} & $\lg I=1.499+0.5114 \lg v$ & 0.9948 & \multirow{2}{*}{$0.04 \sim 0.20$} & $E=0.6189+0.02615 \ln v$ & 0.9909 \\
\hline $\mathrm{Xa}$ & & $\lg I=1.724+0.5632 \lg v$ & 0.9922 & & $E=1.011+0.02685 \ln v$ & 0.9927 \\
\hline
\end{tabular}

TABLE 4: Analytical parameters for individual and simultaneous determination of UA and Xa at PMB-ERGO/GCE.

\begin{tabular}{|c|c|c|c|c|c|c|}
\hline $\begin{array}{l}\text { Measurement } \\
\text { method }\end{array}$ & Analye & $\begin{array}{l}\text { Analysis } \\
\text { Method }\end{array}$ & Linear range $(\mathrm{M})$ & $\begin{array}{c}\text { Linear regression } \\
\text { equation } \\
I: \mu \mathrm{A} C: \mathrm{M}\end{array}$ & $\begin{array}{c}\text { Correlation } \\
\text { coefficient }\end{array}$ & $\begin{array}{c}\text { Detection limit } \\
(\mathrm{M})\end{array}$ \\
\hline \multirow{4}{*}{ Individual } & \multirow{2}{*}{ UA } & $\mathrm{CV}$ & $1.00 \times 10^{-7} \sim 3.00 \times 10^{-4}$ & $\lg I=3.981+0.6148 \lg C$ & 0.9958 & $8.00 \times 10^{-8}$ \\
\hline & & SWV & $8.00 \times 10^{-8} \sim 5.00 \times 10^{-4}$ & $\lg I=3.187+0.4697 \lg C$ & 0.9933 & $3.00 \times 10^{-8}$ \\
\hline & \multirow{2}{*}{$\mathrm{Xa}$} & $\mathrm{CV}$ & $1.00 \times 10^{-7} \sim 3.00 \times 10^{-4}$ & $\lg I=3.615+0.5201 \lg C$ & 0.9942 & $8.00 \times 10^{-8}$ \\
\hline & & SWV & $5.00 \times 10^{-8} \sim 4.00 \times 10^{-4}$ & $\lg I=2.937+0.4155 \lg C$ & 0.9966 & $1.00 \times 10^{-8}$ \\
\hline \multirow{4}{*}{ Simultaneous } & \multirow{2}{*}{ UA } & $\mathrm{CV}$ & $1.00 \times 10^{-7} \sim 2.00 \times 10^{-4}$ & $\lg I=3.572+0.5180 \lg C$ & 0.9926 & $8.00 \times 10^{-8}$ \\
\hline & & SWV & $8.00 \times 10^{-8} \sim 4.00 \times 10^{-4}$ & $\lg I=3.604+0.5702 \lg C$ & 0.9940 & $3.00 \times 10^{-8}$ \\
\hline & \multirow{2}{*}{$\mathrm{Xa}$} & $\mathrm{CV}$ & $5.00 \times 10^{-7} \sim 3.00 \times 10^{-4}$ & $\lg I=4.179+0.6501 \lg C$ & 0.9931 & $1.00 \times 10^{-7}$ \\
\hline & & SWV & $1.00 \times 10^{-7} \sim 4.00 \times 10^{-4}$ & $\lg I=3.240+0.4832 \lg C$ & 0.9937 & $5.00 \times 10^{-8}$ \\
\hline
\end{tabular}

TABLE 5: Comparison of the proposed method with other electrochemical methods for the simultaneous determination of UA and Xa.

\begin{tabular}{|c|c|c|c|}
\hline Electrode & Linear range $(\mathrm{M})$ & Detection limit (M) & Reference \\
\hline Poly (ATD) modified glassy carbon electrode & $\begin{array}{l}\text { UA: } 5.0 \times 10^{-6} \sim 4.5 \times 10^{-5} \\
\text { Xa: } 5.0 \times 10^{-6} \sim 4.5 \times 10^{-5}\end{array}$ & $\begin{array}{l}\text { UA: } 1.9 \times 10^{-7} \\
\text { Xa: } 5.9 \times 10^{-7}\end{array}$ & {$[30]$} \\
\hline Poly (BCP) modified glassy carbon electrode & $\begin{array}{l}\text { UA: } 5.0 \times 10^{-7} \sim 1.2 \times 10^{-4} \\
\text { Xa: } 1.0 \times 10^{-7} \sim 1.0 \times 10^{-4}\end{array}$ & $\begin{array}{l}\text { UA: } 2.0 \times 10^{-7} \\
\text { Xa: } 6.0 \times 10^{-8}\end{array}$ & {$[31]$} \\
\hline $\begin{array}{l}\text { Electrochemically reduced graphene oxide modified } \\
\text { electrode }\end{array}$ & UA: $5.0 \times 10^{-7} \sim 6.0 \times 10^{-5}$ & UA: $5.0 \times 10^{-7}$ & {$[32]$} \\
\hline $\begin{array}{l}\text { Preanodized nontronite coated screen-printed carbon } \\
\text { electrode }\end{array}$ & $\begin{array}{l}\text { UA: } 2.0 \times 10^{-6} \sim 4.0 \times 10^{-5} \\
\text { Xa: } 2.0 \times 10^{-6} \sim 4.0 \times 10^{-5}\end{array}$ & $\begin{array}{l}\text { UA: } 4.2 \times 10^{-7} \\
\text { Xa: } 7.0 \times 10^{-8}\end{array}$ & {$[33]$} \\
\hline $\begin{array}{l}\text { Poly (L-arginine)/graphene composite film modified } \\
\text { electrode }\end{array}$ & $\begin{array}{l}\text { UA: } 1.0 \times 10^{-7} \sim 1.0 \times 10^{-5} \\
\text { Xa: } 1.0 \times 10^{-7} \sim 1.0 \times 10^{-5}\end{array}$ & $\begin{array}{l}\text { UA: } 5.00 \times 10^{-8} \\
\text { Xa: } 5.00 \times 10^{-8}\end{array}$ & {$[34]$} \\
\hline $\begin{array}{l}\text { Poly(methylene blue) and electrochemically reduced } \\
\text { graphene oxide composite film modified electrode }\end{array}$ & $\begin{array}{l}\text { UA: } 8.00 \times 10^{-8} \sim 4.00 \times 10^{-4} \\
\text { Xa: } 1.00 \times 10^{-7} \sim 4.00 \times 10^{-4}\end{array}$ & $\begin{array}{l}\text { UA: } 3.00 \times 10^{-8} \\
\text { Xa: } 5.00 \times 10^{-8}\end{array}$ & This work \\
\hline
\end{tabular}

the mechanisms of UA and Xa oxidation can be proposed as follows in Figures 8 and 9, respectively.

3.6. Individual and Simultaneous Determination of UA and $\mathrm{Xa}$. Figures 10 and 11 describe $\mathrm{CV}$ and SWV responses of $\mathrm{UA}, \mathrm{Xa}$, and their mixture solution at various concentrations, respectively. And Table 4 lists their linear ranges, detection limits, and so forth.

The results in Table 4 demonstrated that the proposed method had wide linear range and high sensitivity. The comparison between this method and other electrochemical methods for simultaneous determination of UA and Xa was listed in Table 5.

3.7. Reproducibility and Stability. The mixed solution of $5.00 \times 10^{-5} \mathrm{M}$ UA and $1.00 \times 10^{-4} \mathrm{M}$ Xa were SWV measured for 20 parallel experiments. The relative standard deviations
(RSD) of the peak currents for UA and Xa were 3.1\% and $2.7 \%$, respectively, implying remarkable reproducibility. After the modified electrode was stored in humid environment at room temperature for 15 days, it retained $94.5 \%$ of its original response and held the similar shape of the original curves, suggesting an acceptable stability of PMB-ERGO/GCE.

3.8. Interference. The influences of various foreign species were investigated in a mixture solution containing $2.00 \times$ $10^{-5} \mathrm{M} \mathrm{UA}$ and $5.00 \times 10^{-5} \mathrm{M} \mathrm{Xa}$. The tolerance limit was set as the maximum concentration of the foreign substances that caused an approximately $\pm 5 \%$ relative error in the determination. The results showed that $\mathrm{K}^{+}, \mathrm{Na}^{+}, \mathrm{Ca}^{2+}, \mathrm{Fe}^{2+}, \mathrm{Mg}^{2+}, \mathrm{Ba}^{2+}$, $\mathrm{Zn}^{2+}, \mathrm{Al}^{3+}, \mathrm{Cl}^{-}, \mathrm{NO}_{3}{ }^{-}, \mathrm{SO}_{4}{ }^{2-}, \mathrm{C}_{2} \mathrm{O}_{4}{ }^{2-}$, starch, L-arginine, Lthreonine, L-serine, L-histidine, dopamine $(\geq 1.0 \mathrm{mg})$ and $\mathrm{L}$ cysteine (0.6 mg), $\mathrm{Cu}^{2+}(0.6 \mathrm{mg}), \mathrm{Ag}^{+}(0.05 \mathrm{mg}), \mathrm{I}^{-}(0.03 \mathrm{mg})$, and ascorbic acid $(0.5 \mathrm{mg})$ had no interference with the 
<smiles>O=C1N=c2[nH]c(=O)[nH]c(=O)c2=N1</smiles>

FIgURE 8: The electrochemical reaction mechanism for UA.

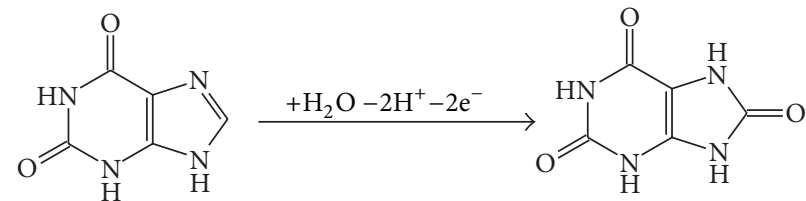

FIGURE 9: The electrochemical reaction mechanism for Xa.

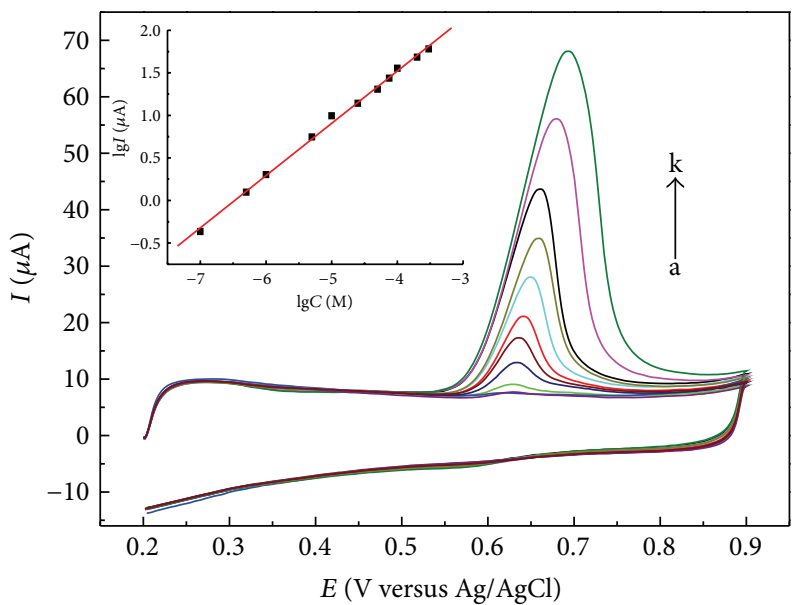

(a)

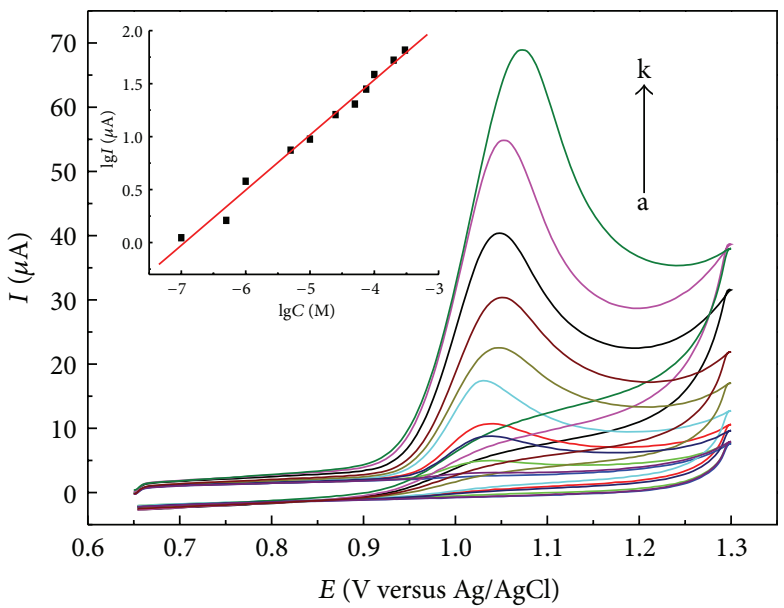

(b)

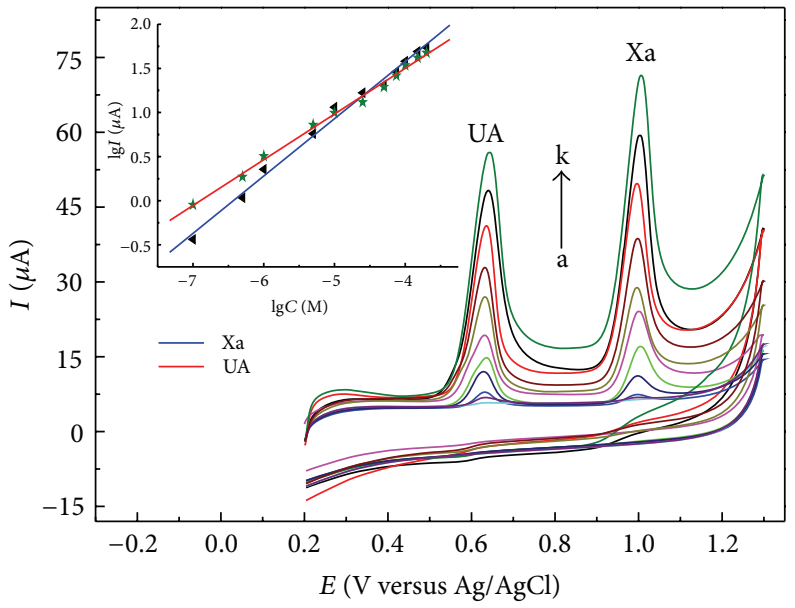

(c)

FIGURE 10: CVs of different concentrations of UA (a), Xa (b), and the mixture solution of UA and Xa (c) (from a to k: 0.08, 0.1, 0.5, 1, 2.5, 5, $7.5,10,25,50,75,100,200,300,400 \mu \mathrm{M})$ at a scan rate of $0.14 \mathrm{~V} \cdot \mathrm{s}^{-1}$ with quiet time for $2 \mathrm{~min}$. Insets show the calibration plots of $\operatorname{lgI}-\lg C$. 
TABLE 6: Simultaneous determination of UA and Xa in human urine samples $(n=5)$.

\begin{tabular}{lcccc}
\hline Analye & $\begin{array}{c}\text { Original value } \\
(\mathrm{M})\end{array}$ & Average (M) & RSD (\%) & Added (M) \\
\hline $\mathrm{UA}$ & $\begin{array}{c}1.46 \times 10^{-5} 1.32 \times 10^{-5} \\
1.44 \times 10^{-5} 1.37 \times 10^{-5} 1.42 \times 10^{-5}\end{array}$ & $1.41 \times 10^{-5}$ & 4.24 & $1.50 \times 10^{-5}$ \\
\hline $\mathrm{Xa}$ & $\begin{array}{c}1.87 \times 10^{-7} 1.77 \times 10^{-7} \\
1.76 \times 10^{-7} 1.91 \times 10^{-7} 1.78 \times 10^{-7}\end{array}$ & $1.82 \times 10^{-7}$ & 3.29 & $1.50 \times 10^{-7}$ \\
\hline
\end{tabular}

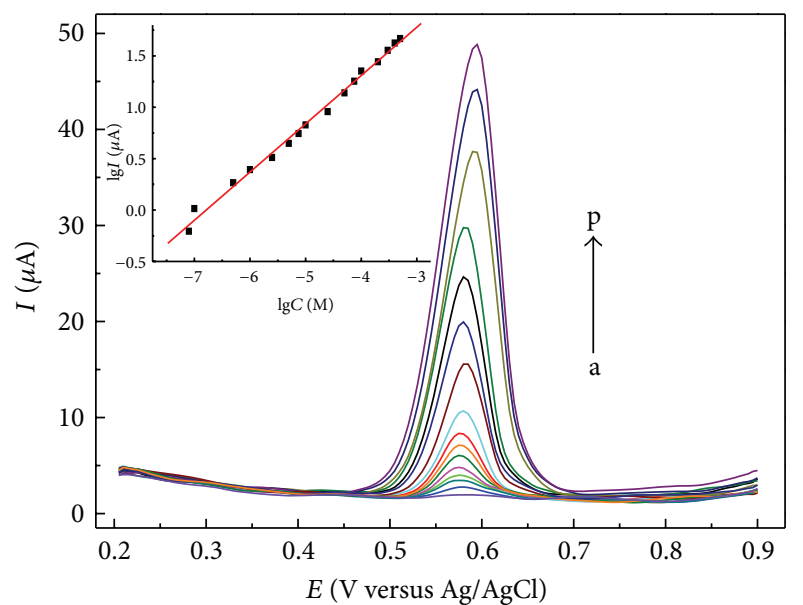

(a)

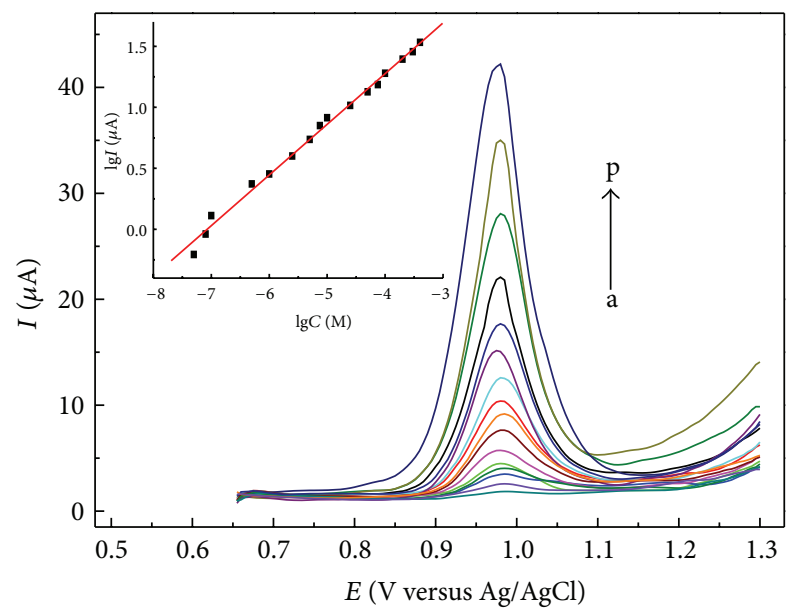

(b)

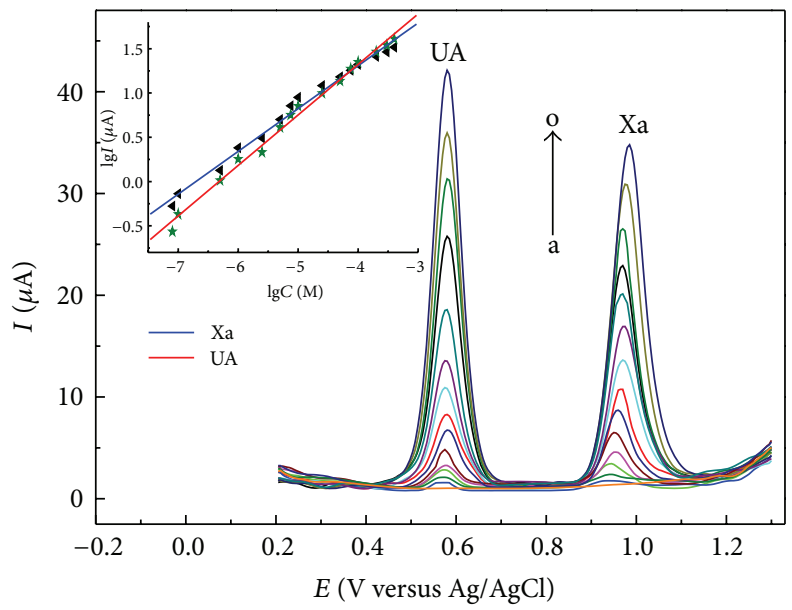

(c)

Figure 11: SWVs of different concentrations of UA (a) (from a to p: 0.08, 0.1, 0.5, 1, 2.5, 5, 7.5, 10, 25, 50, 75, 100, 200, 300, 400, 500 $\mu \mathrm{M}$ ), Xa (b) (from a to p: $0.05,0.08,0.1,0.5,1,2.5,5,7.5,10,25,50,75,100,200,300,400 \mu \mathrm{M}$ ), and the mixture solution of UA and Xa (c) (from a to o: $0.08,0.1,0.5,1,2.5,5,7.5,10,25,50,75,100,200,300,400 \mu \mathrm{M}$ ) with step $E$ for $5 \mathrm{mV}$, amplitude for $30 \mathrm{mV}$, frequency for $5 \mathrm{~Hz}$, and quiet time for $2 \mathrm{~min}$. Insets show the calibration plots of $\lg I-\lg C$.

determination of UA and Xa. Therefore, it is possible to simultaneously determine UA and $\mathrm{Xa}$ in a sample on PMBERGO/GCE.

3.9. Sample Analysis. Human urine sample was selected as the real sample to examine the reliability of the proposed SWV method. $1 \mathrm{~mL}$ urine sample was diluted 10 times with 0.1 M PBS (pH 3.0) before measurement. The obtained results are summarized in Table 6.

\section{Conclusions}

PMB-ERGO/GCE was prepared by electropolymerization. The modified electrode exhibited good conductivity and excellent electrocatalytic activity toward UA and Xa. The introduction of ERGO enhanced the effective surface areas on modified electrode compared with PMB film. The real reaction electron number of $\mathrm{UA}$ and $\mathrm{Xa}$ were calculated to be 1.964 and 1.913, respectively, in $\mathrm{pH} 3.0$ phosphate buffer 
solution. The oxidation of UA and Xa were both controlled by diffusion. PMB-ERGO/GCE displayed desirable properties including excellent stability, reproducibility, selectivity, and sensitivity. The results demonstrated that the proposed method is a rapid, sensitive, and reproducible method for determination of UA and Xa in human urine sample. Therefore, PMB-ERGO/GCE would act as a promising sensor for a wide range of electrochemical sensing and biosensing applications.

\section{Conflict of Interests}

The authors declare that there is no conflict of interests regarding the publication of this paper.

\section{Acknowledgment}

This research is funded by Anhui Province Universities Provincial Natural Science Research Foundation for Key Project (no. KJ2011A255), China.

\section{References}

[1] C. Y. Liu, Z. Y. Liu, R. Peng, and Z. C. Zhong, "Quasireversible process of dopamine on copper-nickel hydroxide composite/nitrogen doped graphene/nafion modified GCE and its electrochemical application," Journal of Analytical Methods in Chemistry, vol. 2014, Article ID 724538, 7 pages, 2014.

[2] L. Hua, X. Wu, and R. Wang, "Glucose sensor based on an electrochemical reduced graphene oxide-poly(l-lysine) composite film modified GC electrode," Analyst, vol. 137, no. 24, pp. 57165719, 2012.

[3] X. Zuo, S. He, D. Li et al., "Graphene oxide-facilitated electron transfer of metalloproteins at electrode surfaces," Langmuir, vol. 26, no. 3, pp. 1936-1939, 2010.

[4] S. Pei, J. Zhao, J. Du, W. Ren, and H.-M. Cheng, "Direct reduction of graphene oxide films into highly conductive and flexible graphene films by hydrohalic acids," Carbon, vol. 48, no. 15, pp. 4466-4474, 2010.

[5] W. Guoxiu, Y. Juan, P. Jinsoo et al., "Facile synthesis and characterization of graphene nanosheets," Journal of Physical Chemistry C, vol. 112, no. 22, pp. 8192-8195, 2008.

[6] G. Williams, B. Seger, and P. V. Kamt, "TiO ${ }_{2}$-graphene nanocomposites. UV-assisted photocatalytic reduction of graphene oxide," ACS Nano, vol. 2, no. 7, pp. 1487-1491, 2008.

[7] X. Zhang, D. c. Zhang, Y. Chen, X. Z. Sun, and Y. W. Ma, "Electrochemical reduction of graphene oxide films: preparation, characterization and their electrochemical properties," Chinese Science Bulletin, vol. 57, no. 23, pp. 3045-3050, 2012.

[8] M. Zhou, Y. L. Wang, Y. M. Zhai et al., "Controlled synthesis of large-area and patterned electrochemically reduced graphene oxide films," Chemistry, vol. 15, no. 25, pp. 6116-6120, 2009.

[9] E. Casero, C. Alonso, L. Vázquez et al., "Comparative response of biosensing platforms based on synthesized graphene oxide and electrochemically reduced graphene," Electroanalysis, vol. 25, no. 1, pp. 154-165, 2013.

[10] L. Gorton, G. Johansson, and A. Torstensson, "A kinetic study of the reaction between dihydronicotinamide adenine dinucleotide $(\mathrm{NADH})$ and an electrode modified by adsorption of 1,2-benzophenoxazine-7-one," Journal of Electroanalytical Chemistry, vol. 196, no. 1, pp. 81-92, 1985.

[11] J. X. Zeng, W. Z. Wei, L. Wu, X. Y. Liu, K. Liu, and Y. $\mathrm{Li}$, "Fabrication of poly(toluidine blue $\mathrm{O}$ )/carbon nanotube composite nanowires and its stable low-potential detection of NADH," Journal of Electroanalytical Chemistry, vol. 595, no. 2, pp. 152-160, 2006.

[12] W. Sun, Y. Wang, Y. Zhang, X. Ju, G. Li, and Z. Sun, "Poly(methylene blue) functionalized graphene modified carbon ionic liquid electrode for the electrochemical detection of dopamine," Analytica Chimica Acta, vol. 751, pp. 59-65, 2012.

[13] V. V. S. Eswara Dutt and H. A. Mottola, "Determination of uric acid at the microgram level by a kinetic procedure based on a "pseudo-induction" period," Analytical Chemistry, vol. 46, no. 12, pp. 1777-1781, 1974.

[14] X. Chen, G. Wu, Z. Cai, M. Oyama, and X. Chen, "Advances in enzyme-free electrochemical sensors for hydrogen peroxide, glucose, and uric acid," Microchimica Acta, vol. 181, no. 7-8, pp. 689-705, 2014.

[15] J. Yu, S. Wang, L. Ge, and S. Ge, "A novel chemiluminescence paper microfluidic biosensor based on enzymatic reaction for uric acid determination," Biosensors and Bioelectronics, vol. 26, no. 7, pp. 3284-3289, 2011.

[16] X. Tang, Y. Liu, H. Hou, and T. You, "A nonenzymatic sensor for xanthine based on electrospun carbon nanofibers modified electrode," Talanta, vol. 83, no. 5, pp. 1410-1414, 2011.

[17] S. Z. Bas, E. Maltas, B. Sennik, and F. Yilmaz, "Design of an electrochemical biosensing system for xanthine detection and a study on binding interaction of ketoconazole with xanthine oxidase," Colloids and Surfaces A: Physicochemical and Engineering Aspects, vol. 444, pp. 40-47, 2014.

[18] X. Liu, W. M. Lin, X. H. Yan, X. H. Chen, J. R. Hoidal, and $\mathrm{P}$. Xu, "Improved method for measurement of human plasma xanthine oxidoreductase activity," Journal of Chromatography B: Analytical Technologies in the Biomedical and Life Sciences, vol. 785, no. 1, pp. 101-114, 2003.

[19] M. Amiri-Aref, J. B. Raoof, and R. Ojani, "A highly sensitive electrochemical sensor for simultaneous voltammetric determination of noradrenaline, acetaminophen, xanthine and caffeine based on a flavonoid nanostructured modified glassy carbon electrode," Sensors and Actuators B: Chemical, vol. 192, pp. 634641, 2014.

[20] J. Galban, Y. Andreu, M. J. Almenara, S. de Marcos, and J. R. Castillo, "Direct determination of uric acid in serum by a fluorometric-enzymatic method based on uricase," Talanta, vol. 54, no. 5, pp. 847-854, 2001.

[21] D. Martinez-Pérez, M. L. Ferrer, and C. R. Mateo, "A reagent less fluorescent sol-gel biosensor for uric acid detection in biological fluids," Analytical Biochemistry, vol. 322, no. 2, pp. 238-242, 2003.

[22] D. L. Rocha and F. R. P. Rocha, "A flow-based procedure with solenoid micro-pumps for the spectrophotometric determination of uric acid in urine," Microchemical Journal, vol. 94, no. 1, pp. 53-59, 2010.

[23] X.-X. Wang, Q. Wu, Z. Shan, and Q.-M. Huang, "BSA-stabilized $\mathrm{Au}$ clusters as peroxidase mimetics for use in xanthine detection," Biosensors and Bioelectronics, vol. 26, no. 8, pp. 3614-3619, 2011.

[24] E. E. Kelley, A. Trostchansky, H. Rubbo, B. A. Freeman, R. Radi, and M. M. Tarpey, "Binding of xanthine oxidase to glycosaminoglycans limits inhibition by oxypurinol," The Journal of Biological Chemistry, vol. 279, no. 36, pp. 37231-37234, 2004. 
[25] Y. Zuo, Y. Yang, Z. Zhu, W. He, and Z. Aydin, "Determination of uric acid and creatinine in human urine using hydrophilic interaction chromatography," Talanta, vol. 83, no. 5, pp. 17071710, 2011.

[26] T. Yamamoto, Y. Moriwaki, S. Takahashi et al., "Determination of human plasma xanthine oxidase activity by highperformance liquid chromatography," Journal of Chromatography B: Biomedical Applications, vol. 681, no. 2, pp. 395-400, 1996.

[27] X. Q. Tian, C. M. Cheng, H. Y. Yuan et al., "Simultaneous determination of L-ascorbic acid, dopamine and uric acid with gold nanoparticles- $\beta$-cyclodextrin-graphene-modified electrode by square wave voltammetry," Talanta, vol. 93, pp. 79-85, 2012.

[28] M. Mohamadi, A. Mostafavi, and M. Torkzadeh-Mahani, "Voltammetric behavior of uric acid on carbon paste electrode modified with salmon sperm dsDNA and its application as label-free electrochemical sensor," Biosensors and Bioelectronics, vol. 54, pp. 211-216, 2014.

[29] R. Devi, S. Yadav, and C. S. Pundir, "Au-colloids-polypyrrole nanocomposite film based xanthine biosensor," Colloids and Surfaces A: Physicochemical and Engineering Aspects, vol. 394, pp. 38-45, 2012.

[30] P. Kalimuthu and S. A. John, "Simultaneous determination of ascorbic acid, dopamine, uric acid and xanthine using a nanostructured polymer film modified electrode," Talanta, vol. 80, no. 5, pp. 1686-1691, 2010.

[31] Y. Wang and L.-L. Tong, "Electrochemical sensor for simultaneous determination of uric acid, xanthine and hypoxanthine based on poly (bromocresol purple) modified glassy carbon electrode," Sensors and Actuators B: Chemical, vol. 150, no. 1, pp. 43-49, 2010.

[32] L. Yang, D. Liu, J. Huang, and T. You, "Simultaneous determination of dopamine, ascorbic acid and uric acid at electrochemically reduced graphene oxide modified electrode," Sensors and Actuators B: Chemical, vol. 193, pp. 166-172, 2014.

[33] J.-M. Zen, Y.-Y. Lai, H.-H. Yang, and A. S. Kumar, "Multianalyte sensor for the simultaneous determination of hypoxanthine, xanthine and uric acid based on a preanodized nontronitecoated screen-printed electrode," Sensors and Actuators B: Chemical, vol. 84, no. 2-3, pp. 237-244, 2002.

[34] F. Y. Zhang, Z. H. Wang, Y. Z. Zhang et al., "Simultaneous electrochemical determination of uric acid, xanthine and hypoxanthine based on poly(L-arginine)/graphene composite film modified electrode," Talanta, vol. 93, pp. 320-325, 2012.

[35] L.-X. Sun, A. M. Reddy, N. Matsuda, A. Takatsu, K. Kato, and T. Okada, "Simultaneous determination of methylene blue and new methylene blue by slab optical waveguide spectroscopy and artificial neural networks," Analytica Chimica Acta, vol. 487, no. 1, pp. 109-116, 2003.

[36] E. Laviron, "Adsorption, autoinhibition and autocatalysis in polarography and in linear potential sweep voltammetry," Journal of Electroanalytical Chemistry, vol. 52, no. 3, pp. 355393, 1974.

[37] G. Dryhurst, "Electrochemical oxidation of uric acid and xanthine at the pyrolytic graphite electrode: mechanistic interpretation of electrochemistry," Journal of the Electrochemical Society, vol. 119, no. 12, pp. 1659-1664, 1972.

[38] Z. H. Wang, S. F. Xiao, and Y. Chen, “ $\beta$-Cyclodextrin incorporated carbon nanotubes-modified electrodes for simultaneous determination of adenine and guanine," Journal of Electroanalytical Chemistry, vol. 589, no. 2, pp. 237-242, 2006. 

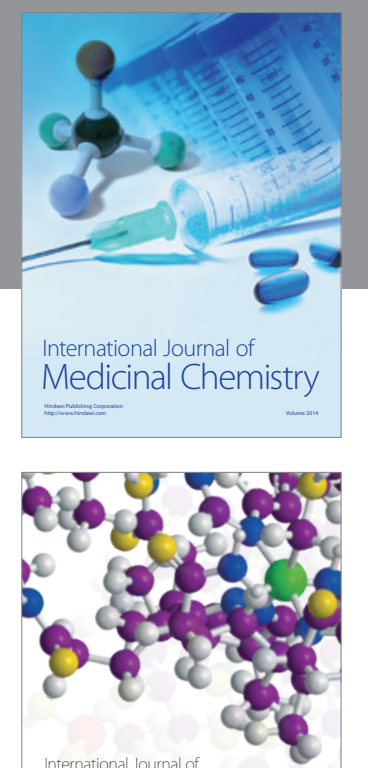

\section{Carbohydrate} Chemistry

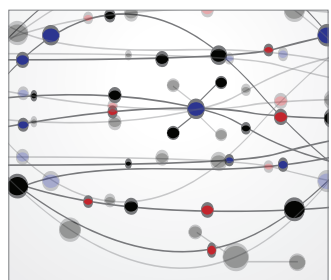

The Scientific World Journal
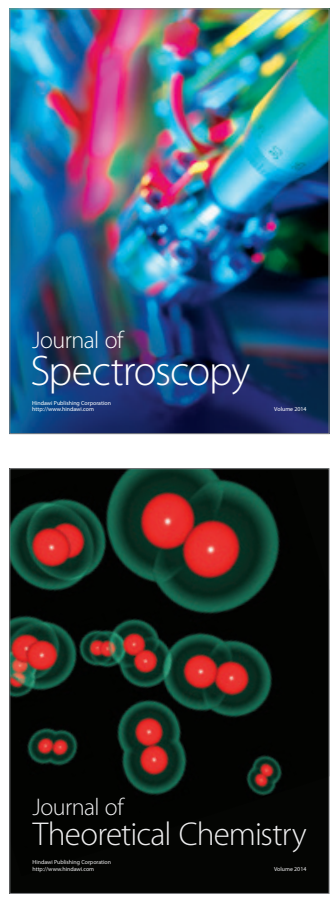
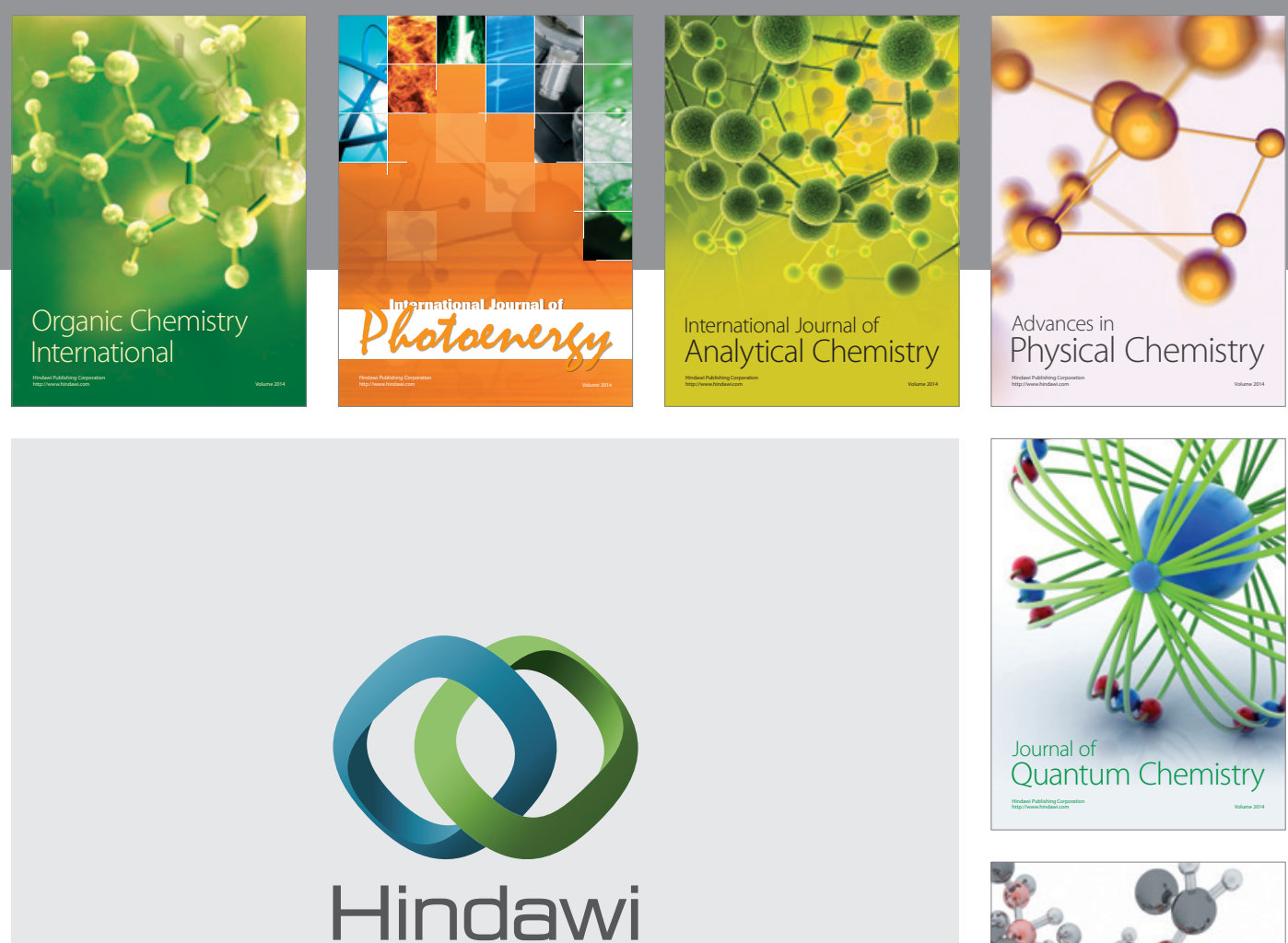

Submit your manuscripts at

http://www.hindawi.com

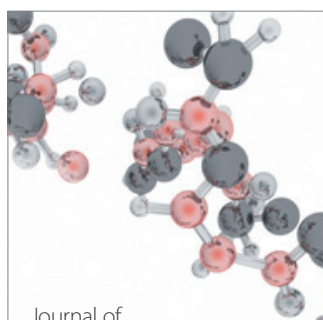

Analytical Methods

in Chemistry

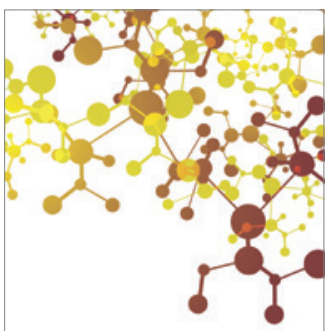

Journal of

Applied Chemistry

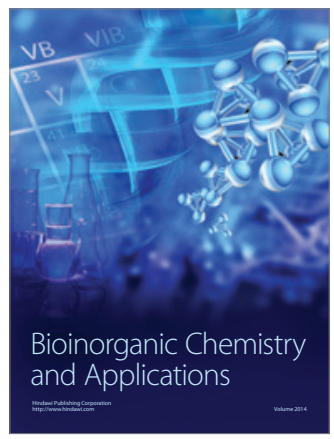

Inorganic Chemistry
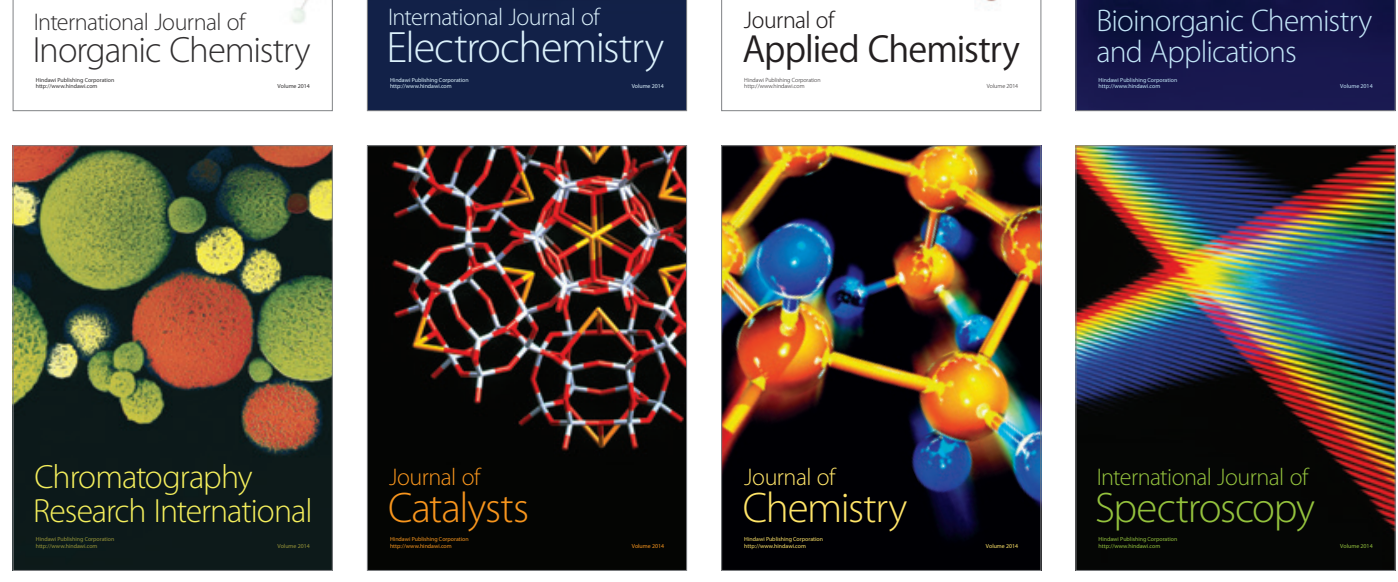